\title{
A Simple Method for Human Peripheral Blood Monocyte Isolation
}

\author{
Marcos C de Almeida $/{ }^{*}$, Alan C Silva, Aldina Barral, Manoel Barral Netto/ ${ }^{+}$
}

Centro de Pesquisas Gonçalo Moniz-Fiocruz, Rua Valdemar Falcão 121, 40295-001 Salvador, BA, Brasil

*Departamento de Patologia, FCS, Universidade de Brasília, DF, Brasil

We describe a simple method using percoll gradient for isolation of highly enriched human monocytes. High numbers of fully functional cells are obtained from whole blood or buffy coat cells. The use of simple laboratory equipment and a relatively cheap reagent makes the described method a convenient approach to obtaining human monocytes.

Key words: monocytes - percoll - gradient-isolation

Macrophages and monocytes are largely used in immunological research especially for the study of intracellular parasites. The ideal method for monocyte isolation combining simplicity, cheapness, purity and high yield does not exist (Seljelid \& Pertoft 1981, Bennett \& Breit 1994). We propose here a simple two step procedure for obtaining highly purified human monocytes.

The most common procedure is monocyte isolation by adherence after Ficoll-Hypaque purification of peripheral blood mononuclear cells (PBMC) (Bennett \& Breit 1994). Monocyte isolation by adherence, although simple, has several disadvantages: high lymphocyte contamination, low flexibility, high manipulation and monocyte transient activation (Haskill et al. 1988, Bennett \& Breit 1994). Lymphocyte contamination in the first hour after adherence may be high, being as high as $40-50 \%$ after two washes and $30 \%$ even after five washings. It has been reported that in the first 24 $\mathrm{h}$, after four vigorous washes, $25 \%$ of remaining cells are lymphocytes (Bennett et al. 1992). The degree of lymphocyte contamination when separating monocytes by the adherence method is probably related to percentage of lymphocytes in PBMC, the amount of PBMC laid for adherence, number of washes, strength of washing and time

\footnotetext{
This work was supported by Pronex and TMRC (AI30639, NIH-USA). MCA was supported by a Capes fellowship. MBN and $\mathrm{AB}$ are Senior Investigators of CNPq. ${ }^{+}$Corresponding author. Fax: +55-21-356.2593. E-mail: mbarral@cpqgm.fiocruz.br

Received 24 June 1999

Accepted 13 December 1999
}

of adhesion. These aspects can make this method variable from donor to donor and from researcher to researcher. Alternative methods are immuneselection, centrifugal elutriation and density gradients. Immune selection is too expensive for daily routine and for large volumes of blood. Centrifugal elutriation, although the method of choice for larger volumes of blood, requires expensive equipment and a specialized technician. Several kinds of density gradients are available, both continuous and discontinuous. Pumps and ultracentrifuges, in general expensive equipment, are necessary for performing continuos gradients.

We report here on the results using a two step procedure with single gradients in each step. First using a Ficoll-Hypaque gradient (density $=1.070$ $\mathrm{g} / \mathrm{ml}$ ) and afterwards a slight hyperosmolar Percoll gradient $($ density $=1.064 \mathrm{~g} / \mathrm{ml})$. Percoll solutions were done as follows: first an isosmotic Percoll was prepared as usually mixing one volume $\mathrm{NaCl}$ $1.5 \mathrm{M}$ with nine volumes of Percoll (Pharmacia, density $=1.130 \mathrm{~g} / \mathrm{ml})$. The Percoll gradient was done mixing 1:1 (v/v) isosmotic Percoll with PBS/ Citrate $\left(\mathrm{NaH}_{2} \mathrm{PO}_{4} 1.49 \mathrm{mM} ; \mathrm{Na}_{2} \mathrm{HPO}_{4} 9.15 \mathrm{mM}\right.$; $\mathrm{NaCl} 139.97 \mathrm{mM} ; \mathrm{C}_{6} \mathrm{H}_{5} \mathrm{Na}_{3} \mathrm{O}_{7} .2 \mathrm{H}_{2} \mathrm{O} 13 \mathrm{mM} ; \mathrm{pH}$ 7.2). Both gradients were centrifuged at $25-35^{\circ} \mathrm{C}$, $400 \mathrm{~g}$ for $35 \mathrm{~min}$. Percentage of monocytes after the Percoll gradient was higher than $90 \%$ using morphology, histochemistry or FACS analysis (Table I, Figure). The cells were viable and functional and able to be cultivated in suspension or attached to plastic, plastic bound fibronectin, collagen or laminin (not shown). Further indications of functionality were secretion of large amounts of TNF- $\alpha$ after LPS stimulation, phagocytose of latex particles and Leishmania promastigotes both in suspension and after adherence (Table II). Eighty 
TABLE I

Monocyte yields and phenotypic analysis after Percoll gradient in relation to blood volumes, buffy-coats or number of peripheral blood mononuclear cells from different donors

\begin{tabular}{|c|c|c|c|c|}
\hline $\begin{array}{l}\text { Source of } \\
\text { material }\end{array}$ & $\begin{array}{c}\text { Monocytes } \\
\text { recovered } \\
\left(\mathrm{X} 10^{6}\right)\end{array}$ & $\begin{array}{c}\text { Viabilility }^{a} \\
(\%)\end{array}$ & $\begin{array}{c}\text { Peroxidase } \\
\text { activity } \\
(\%)^{+}\end{array}$ & $\begin{array}{l}\text { Cytofluorimetry } \\
\text { analysis }\end{array}$ \\
\hline \multicolumn{5}{|l|}{ Blood (ml) } \\
\hline 20 & 4 & 85 & 92 & ND \\
\hline 20 & 7.8 & 94.2 & 92.5 & ND \\
\hline 20 & 10.2 & 96 & ND & $96.7 \%$ CD64+ \\
\hline 40 & 12 & 90 & 95 & ND \\
\hline 40 & 7.2 & 92 & 90 & ND \\
\hline 53 & 22.8 & 95 & 98 & $96.6 \% \mathrm{CD} 14+$ \\
\hline \multicolumn{5}{|l|}{$\operatorname{PBMC}\left(\mathrm{X} 10^{6}\right)$} \\
\hline 24.8 & 7.8 & $>90$ & ND & $96.9 \% \mathrm{HG}$ \\
\hline 76 & 25.1 & $>90$ & ND & $95.4 \% \mathrm{HG}$ \\
\hline 170 & 37.2 & 100 & ND & $94.8 \%$ CD14+CD3- \\
\hline 204 & 32 & $>90$ & ND & $94 \%$ CD14+CD3- ${ }^{b}$ \\
\hline 345 & 64 & $>90$ & ND & $93.9 \% \mathrm{HG}$ \\
\hline 372 & 134 & $>90$ & ND & 98\% CD14+CD3- \\
\hline \multicolumn{5}{|l|}{ Buffy-coat } \\
\hline $1 / 2$ blood bag & 88 & $>90$ & ND & 98\% CD14+CD3- \\
\hline $1 / 2$ blood bag & 94.6 & $>90$ & ND & $89.9 \%$ CD14+CD3- \\
\hline
\end{tabular}

$a$ :measured by Trypan blue dye exclusion test.; $b: 1.2 \%$ of CD19+CD3; HG: height and granularity; ND: note done; PBMC: peripheral blood mononuclear cells; +: presence of peroxidase activity was detected incubating at room temperature air dried cytospin preparations with 3,3"-diaminobenzidine plus $\mathrm{H}_{2} \mathrm{O}_{2}$.
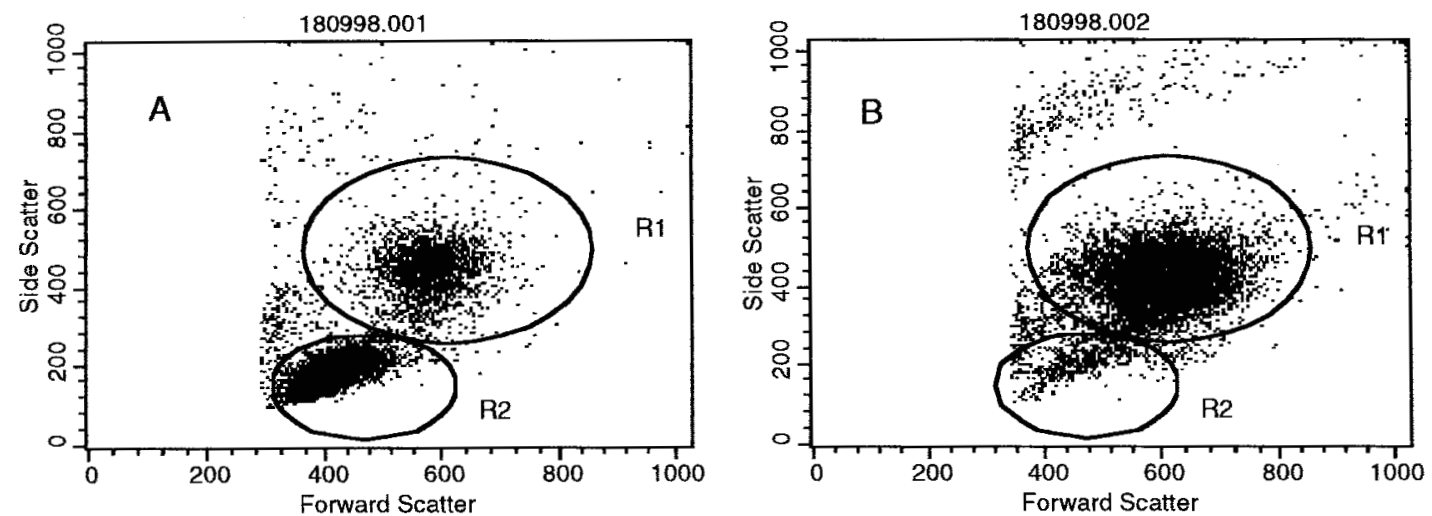

Representative side (granularity) and forward (height) light scatters (A) following Fycoll-Hypaque and (B) following Percoll gradient. The R1 gate corresponds to monocyte and $\mathrm{R} 2$ to lymphocyte populations. The $\mathrm{R} 1+\mathrm{R} 2 \mathrm{~T}$ ) were considered to represent $100 \%$ of cell population (96.6\% of acquisition events in (A) and $93.4 \%$ in (B); (A) R1/T x 100=21 and in (B) R1/T x 100=93.9.

to $90 \%$ from the monocytes laid on the Percoll gradient were recovered afterwards (Table III). The procedure yields similar results with small and large amounts of blood. When working with small amounts of blood $(<50 \mathrm{ml})$ for saving time we have used leukocyte rich plasma after dextran sedimentation.(Meerschaert \& Furie 1994). When working with very large amounts of blood (> 200 $\mathrm{ml}$ ) was better to take the buffy coat. It has been previously proposed a two step Percoll gradient for monocyte isolation with $90 \%$ of purity but with variable yield (Seljelid \& Pertoft 1981). The most important pitfall of their method was that they advocate the use of defribrinated blood. This could lead to serious cell loss and activation. As they had observed, monocytes bind strongly to small microscopic blood clots. Platelets could also bind to monocytes forming clumps (Weyrich et al. 1996). The adequate blood anticoagulation is then critical. The use of sodium citrate in all the solutions 
until the Percoll gradient avoids the use of defibrinatrion and platelet binding to monocytes (Roos \& de Boer 1986), possibly the use of EDTA could have the same effect although we have not tested it. Platelet elimination can be easily done with low speed centrifugation $(100 \mathrm{~g})$ before or after the Percoll gradient although it implies in cell loss. Temperature is also a critical point. We prefer working during all the procedure at room temperature $\left(25-35^{\circ} \mathrm{C}\right)$ as it has been shown that monocyte tends spontaneously to aggregate at lower temperatures (Mentzer et al. 1986) and platelets to be activated (White \& Krivit 1967, Oliver et al. 1999). Finally as it has been shown (Fluks 1981, Boyum 1983) the monocyte purity can be improved by hyperosmotic density gradients. In conclusion the procedure devised here can be done with usual reagents and equipment of average laboratory, it is easily handled and provides a $90 \%$ pure population of monocytes.

\section{TABLE II}

Monocyte functional assays after Percoll gradient

TNF- $\alpha$ production $48 \mathrm{~h}$ after

LPS stimulation $(10 \mathrm{ng} / \mathrm{ml})$

Adherence to plastic

$1,019 \mathrm{pg} / \mathrm{ml}^{a}$

Phagocytose of latex beads

Yes

Phagocytose of Leishmania $(L)$ chagasi

$91 \%^{b}$

promastigotes

Increased CD 54 expression $48 \mathrm{~h}$

after IFN- $\gamma(100 \mathrm{U} / \mathrm{ml})$ stimulation

$\bar{a}$ : mean of five experiments (SD=778.7); $10^{6}$ monocytes/ $\mathrm{ml}$ were cultivated in RPMI medium plus $2 \mathrm{mM}$ Lglutamine with $10 \%$ human blood serum; $b$ : $\%$ of cells exhibiting latex beads after $12 \mathrm{~h}$ incubation with 10 beads/monocyte; one representative experiment; $c$ : \% of cells exhibiting amastigotes after $12 \mathrm{~h}$ incubation with ten promastigotes/monocyte; one representative experiment; $d$ : mean percent increase of four experiments $(\mathrm{SD}=17.74)$.

TABLE III

Rate of monocyte recovery after Percoll gradient

\begin{tabular}{lcccc}
\hline $\begin{array}{l}\text { PBMC } \\
\left(\times 10^{6}\right)\end{array}$ & $\begin{array}{c}\text { Monocytes }^{a} \\
(\%)\end{array}$ & $\begin{array}{c}\text { Monocytes ater } \\
\text { percoll gradient }\left(\times 10^{6}\right)\end{array}$ & $\begin{array}{c}\text { Yield } \\
(\%)\end{array}$ & $\begin{array}{c}\text { Purity } \\
(\% \text { HG })\end{array}$ \\
\hline 24.8 & 31 & 7.8 & 82.4 & 96.9 \\
76 & 40.3 & 25.1 & 82.0 & 95.4 \\
345 & 20.4 & 63.9 & 91 & 95.2 \\
\hline
\end{tabular}

HG: height and granularity; PBMC: peripheral blood mononuclear cells, obtained from Ficoll-Hypaque gradient; $a$ : the monocyte percentage from PBMC was determined as shown in Fig. 1.

\section{ACKNOWLEDGEMENTS}

To Silvia A Cardoso and Jorge C Andrade for technical assistance.

\section{REFERENCES}

Bennett S, Breit SN 1994. Variables in the isolation and culture of human monocytes that are of particular relevance to studies of HIV. J Leukoc Biol 56: 236240.

Bennett S, Por SB, Stanley ER, Breit SN 1992. Monocyte proliferation in a cytokine-free, serum-free system. J Immunol Methods 153: 201-212.

Boyum A 1983. Isolation of human blood monocytes with Nycodenz, a new non-ionic iodinated gradient medium. Scand J Immunol 17: 429-436.

Fluks AJ 1981. Three-step isolation of human blood monocytes using discontinuous density gradients of Percoll. J Immunol Methods 41: 225-233.

Haskill S, Johnson C, Eierman D, Becker S, Warren K 1988. Adherence induces selective mRNA expression of monocyte mediators and proto-oncogenes. $J$ Immunol 140: 1690-1694.

Meerschaert J, Furie MB 1994. Monocytes use either
CD11/CD18 or VLA-4 to migrate across human endothelium in vitro. J Immunol 152: 1915-1926.

Mentzer SJ, Guyre PM, Burakoff SJ, Faller DV 1986. Spontaneous aggregation as a mechanism for human monocyte purification. Cell Immunol 101: 312-319.

Oliver AE, Tablin F, Walker NJ, Crowe JH 1999. The internal calcium concentration of human platelets increases during chilling. Biochim Biophys Acta 1416: 349-360.

Roos D, de Boer M 1986. Purification and cryopreservation of phagocytes from human blood. Methods Enzymol 132: 225-243.

Seljelid R, Pertoft H 1981. In DO Adams, PJ Edelson \& HS Koren (eds), Methods for Studying Mononuclear Phagocytes, Academic Press, p. 201-205.

Weyrich AS, Elstad MR, McEver RP, McIntyre TM, Moore KL, Morrissey JH, Prescott SM, Zimmerman GA 1996. Activated platelets signal chemokine synthesis by human monocytes. J Clin Invest 97: 15251534.

White JG, Krivit W 1967. An ultrastructural basis for the shape changes induced in platelets by chilling. Blood 30: 625-635. 